\title{
La adaptación de los medios de comunicación al siglo XXI
}

\author{
José Pereira \\ Director del Área de Innovación y Negocio de \\ la Corporación Radio e Televisión de Galicia (CRTVG)
}

\section{Referencia de este artículo}

Pereira, José (2020). La adaptación de los medios de comunicación al siglo XX. En adComunica. Revista Científica del Estrategias, Tendencias e Innovación en Comunicación, $\mathrm{n}^{0} 20$, Castellón: Universitat Jaume I, 385-388. DOI: http://dx.doi. org/10.6035/2174-0992.2020.20.17.

Los procesos de adaptación a las nuevas dinámicas económicas siempre son complejos, arriesgados y de velocidad variable. Las grandes transformaciones requieren consensos, compromisos y asimilación rápida de elementos que transforman las estructuras clásicas (Steil, 2016).

En el momento actual, la estrategia de adaptación que usa la industria TIC y de consumo digital se fundamenta en la gratificación de nichos concretos de población creados a partir de pautas de comportamiento comunes y que afectan tanto a la información como al entretenimiento.

El modelo de medios informativos en el siglo XX consistía en la creación de medios posicionados ideológicamente en uno de los espectros clásicos de la política (eje izquierda-derecha) y defendía la interpretación de los acontecimientos bajo una posición determinada, salvaguardando siempre los principios de veracidad, objetividad e imparcialidad.

En los casos de las empresas de contenidos de entretenimiento y ficción, el modelo se fundamentaba en la producción de contenidos, vendidos a distribuidores y difusores y consumidos en tres formatos únicos: o en el cine, o en la televisión, o en el hogar 
a través de tecnologías limitadas como el DVD. En cualquiera caso, el proceso de consumo de entretenimiento audiovisual requería un esfuerzo elevado del usuario como el alquiler, la compra de entradas, desplazamiento a salas de cine..., excepto en la televisión que llegaba a los hogares de una manera gratuita, automática y sencilla.

Sin embargo, en la economía que se establece en el siglo XXI basada en las nuevas posibilidades tecnológicas se rompen estas lógicas. En los albores del siglo XXI aparecen modelos nuevos de producción, de distribución y de consumo de contenidos y nace un nuevo tipo de usuario capaz de comunicar con las mismas posibilidades de difusión que las grandes corporaciones y de una manera mucho más barata. En la medida que aparecieron empresas que ofrecían herramientas de difusión tan potentes como los grandes servidores de los medios de comunicación tradicionales, los usuarios fueron adquiriendo la capacidad de trasladar sus mensajes a un número importante de personas, sin estar limitados ni por la distancia geográfica ni por límites temporales ni por los principios fundacionales del periodismo. Se produjo así un fenómeno desconocido en la comunicación de masas, ya que se transformaron las estructuras de difusión, antes en manos de las empresas profesionales de comunicación, y ahora en manos de las empresas tecnológicas y de los propios usuarios.

Estas nuevas posibilidades permitieron establecer un nuevo marco económico en el que las empresas de comunicación comenzaron a entrar en una deriva de reducción de valorización mercantil, acompañado de un continuo proceso de reducción de ingresos.

Además, se transformaron las fuentes tradicionales de financiación. La inteligencia artificial propició la aparición de un nuevo paradigma de la publicidad, la denominada publicidad programática, capaz de adaptar los mensajes a cada espectador, permitiendo lanzar mensajes que se ajustan de una manera nunca vista a los intereses del receptor. Bien es cierto que en los últimos cinco años se produjeron momentos de crisis de las nuevas fórmulas publicitarias digitales, pero los datos del lustro demuestran que la publicidad digital aumenta a ritmos de casi un $9 \%$ anuales, frente a la bajada generalizada de otros soportes, fundamentalmente la prensa y la televisión, que en el año 2019 tuvo una bajada en España de inversión publicitaria del 5,8\% (Infoadex, 2020). Además, por primera vez en la historia, el informe certifica que la inversión publicitaria en soportes digitales $(2.296,2$ millones de euros) superó a la inversión en televisión (2.002,8 millones de euros), y casi quintuplicó a la inversión publicitaria en radio (486,4 millones de euros). Una clara muestra de un cambio de ciclo en los modelos de negocio de la comunicación.

Estos datos quedan complementados por el informe IP2 de la consultora Arce Media sobre el mercado publicitario en el año 2019, en el que se indica que los soportes más castigados por la llegada de internet están muy avanzados en su proceso de reconversión. La prensa en papel, por ejemplo, logró en el año 2019 
que el $49 \%$ de sus ingresos se produjeran a través de su oferta digital (353,6 millones en digital frente a los 792 millones totales de inversión publicitaria). En la televisión, esas cifras están aún muy lejos y la publicidad en los soportes digitales de las televisión no alcanzaron un 3\% de la inversión publicitaria global -54,7 millones de euros frente a los 2.054,6 millones de euros totales (Arce Media, 2019).

En el momento en el que la tecnología permite personalizar mensajes, recomendar a partir de los gustos y permitir difundir contenidos de una manera eficaz y sencilla, aparecen nuevos paradigmas económicos que logran establecer nuevos modelos de relación comercial con los clientes. Uno de los más destacados es la recuperación del concepto de la gratificación, nacido hay más de setenta años (Katz y Lazarsfeld, 2005) pero actualizado al paradigma de la «gratificación instantánea» o la «gratificación del clic» que permite establecer nuevos patrones de venta basados en la compra impulsiva, pero sobre todo, en la compra inmediata una vez que el usuario se encuentra satisfecho con el producto (Krug, 2015).

Este modelo tiene como consecuencia colateral el mercado de datos y esta situación alcanzó en el siglo XXI una ecuación perfecta, ya que junto a la valorización de los datos y junto al nuevo modelo de negocio fundamentado en la personalización de los mensajes, se le suma la nueva percepción de la ciudadanía sobre su privacidad, que alcanzó las cuotas más bajas de preocupación desde que se hacen estudios sociológicos (Sarabia-Sánchez, et al., 2019).

A esta situación, también debemos añadir los cambios de funciones y de categorías profesionales que permitan la adaptación de la empresa a las nuevas rutinas de consumo. Estos cambios, siempre condicionados por la propia estructura de cada compañía, se convierten en fundamentales para garantizar la viabilidad futura, con ejemplos tan claros como el del Washington Post, que inició una senda de conexión con otros productos nativos digitales de gran éxito, como Amazon, el lector Kindle o bases de datos internacionales (Benner y Wingfield, 2016).

\section{Referencias}

Arce Media. (2019). Informe I2P. Índice de inversión publicitaria 2019. Consultado el 20 de julio de 2020 en http://www.arcemedia.es/wp-content/uploads/2020/02/ informe_i2p_2019.pdf

Benner, Katie y Wingfield, Nick (2016). El dueño de Amazon, Jeff Bezos, defiende su decisión de comprar el Washington Post. The New York Times. Consultado el 20 de julio de 2020 en https://www.nytimes.com/es/2016/06/06/espanol/jeff-bezos-defiende-su-decision-de-comprar-el-washington-post.html

Infoadex. (2020). Estudio Infoadex de la inversión publicitaria en España 2020. Infoadex. Consultado el 20 de julio de 2020 en https://www.infoadex.es/home/ wp-content/uploads/2020/02/Estudio-InfoAdex-2020-Resumen.pdf 
Katz, Elihu y Lazarsfeld, Paul F. (2005). Personal Influence: The Part Played by People in the Flow of Mass Communications. Nueva York: Routledge.

Krug, Steve (2015). No me hagas pensar. Actualización. Madrid: Anaya Publicaciones Generales.

Sarabia-Sánchez, Francisco Javier, Aguado, Juan-Miguel y Martínez-Martínez, Inmaculada J. (2019). Privacy paradox in the mobile environment: The influence of the emotions. En: El Profesional de La Información, vol.28, n². Barcelona: EPI. doi: https://doi.org/10.3145/epi.2019.mar.12

Steil, Benn (2016). La batalla de Bretton Woods: John Maynard Keynes, Harry Dexter White y cómo se fraguó un nuevo orden mundial. Barcelona: Deusto. 